\title{
Pengaruh Metode Minimum Quantity Lubrication (MQL) Terhadap Nilai Kekasaran Permukaan
}

\author{
Dicky A. Nugraha ${ }^{1)}$, Rika D.H. Qoryah ${ }^{2)}$, Mahros Darsin ${ }^{3 *}$ \\ 1,2,3) Jurusan Teknik Mesin Fakultas Teknik Universitas Jember \\ 3) mahros.teknik@unej.ac.id
}

DOI: https://doi.org/10.21107/rekayasa.v13i2.6259

\section{Effect of Minimum Quantity Lubrication (MQL) Method on Surface Roughness}

\begin{abstract}
A device to control the spraying of cutting fluid in minimum quantity lubrication (MQL) has been initiated. This device was programmed with Ardunio and connected to a thermal sensor which is stick on the flank face of the tool. It succeeded in controlling when the cutting fluid should be sprayed and stopped. This research aim is to investigate the effect of using this device to the machined surface roughness. The Taguchi method L9 was used for designing the experiments. Variations were made on the method of applying cutting flood, depth of cut, and cutting fluid composition. Carbide insert tools were used and roughness tester was employed to measure the machined surface roughness. Analysis of S/N ratio following with analysis of variance (ANOVA) revealed that the controlled MQL cooling application results in the minimum surface roughness. The optimum surface roughness would be achieved when using MQL with temperature controller, depth of cut of $2.0 \mathrm{~mm}$, and composition between water and oil for cutting fluid of 7:3.
\end{abstract}

Keywords: Minimum Quantity Lubrication (MQL), Surface roughness, Lubrication, Cutting fluid, Depth of cut, Surface roughness tester.

\section{ABSTRAK}

Sebuah alat kendali semprotan cutting fluid pada minimum quantity lubrication (MQL) telah berhasil dibuat. Alat yang bekerja dengan sistem Arduino ini dihubungkan dengan sensor suhu yang diletakkan pada sisi pahat dan berhasil mengendalikan kapan cutting fluid harus disemprotkan dan kapan harus berhenti. Tujuan dari penelitian ini adalah untuk mempelajari efek penggunaan alat kendali ini terhadap kekasaran permukaan pada pembubutan baja AISI 4340. Metode Taguchi L9 digunakan untuk menyusun desain eksperimen dengan variasi parameter: metode pemberian cutting fluid, kedalaman permukaan dan komposisi campuran cutting fluid. Pahat sisipan berbahan karbida digunakan untuk memesin lurus dan roughness tester digunakan untuk mengukur kekesaran permukaan hasil pembubutan. Analisis S/N ratio dilanjutkan dengan analisis varians (ANAVA) membuktikan bahwa metode MQL yang dilengkapi sistem kendali ini mampu menghasilkan rata-rata permukaan paling halus dibandingkan metode lain. Nilai kekasaran optimum sebesar 1,941 $\mu$ m diperoleh pada kombinasi permesinan dengan MQL dengan sistem kendali, depth of cut 2,0 mm, dan komposisi air terhadap minyak pada cutting fluid 7:3. Kata Kunci: Minimum Quantity Lubrication (MQL), Surface roughness, Pelumasan, Cutting fluid, Depth of cut, Surface roughness tester.

\section{PENDAHULUAN}

Pada jaman persaingan global, semua produsen harus bersaing dengan pesaing tingkat internasional, tidak terkecuali industri manufaktur. Produsen yang menghasilkan produk dengan kualitas baik dengan harga bersaing akan menjadi pemenang dan bertahan di pasar, dan sebaliknya. Karakter penentu utama kualitas produk permesinan adalah kekasaran permukaan. Karakter ini mudah diukur dan menjadi standar mutu produk. (Wahyudi, 2011),

\section{Article History:}

Received: January, $2^{\text {nd }}$ 2020; Accepted: May, $10^{\text {th }} 2020$

REKAYASA ISSN: 2502-5325 has been Accredited by Ristekdikti (Arjuna) Decree: No. 23/E/KPT/2019 August $8^{\text {th }}$, 2019 effective until 2023
(Ali, S.M., Dhar, N.R., Dey, 2011), (Patole \& Kulkarni, 2018).

Pada proses pembubutan logam, pada benda kerja akan terjadi panas yang tinggi sebagai akibat adanya gesekan antara pahat dan benda kerja yang dipotong. Jika temperatur yang terjadi pada benda kerja tidak dikendalikan, maka permukaan antara pahat dan benda kerja cenderung akan menyatu. Untuk mengurangi temperatur gesekan antara benda kerja dan pahat maka perlu digunakan media pendingin (Upadhyay, Jain, \& Mehta, 2012).

\section{Cite this as:}

Nugraha, D.A., Qoryah, R.D.H., \& Darsin, M. (2020). Pengaruh Metode Minimum Quantity Lubrication (MQL) Terhadap Nilai Kekasaran Permukaan. Rekayasa, 13(2), 125-129. doi: https://doi.org/10.21107/rekayasa.v13i2.6259 
Salah satu cara untuk mendapatkan permukaan yang memenuhi spesifikasi diantaranya adalah dengan pemberian fluida pemotongan (cutting fluid) pada saat permesinan (Jiang, Zhou, Zhang, Wang, \& Sutherland, 2015). Cutting fluid sangat penting pada proses permesinan untuk menurunkan panas dan gesekan. Fungsi dari cutting fluid selain untuk pelumas juga dapat digunakan sebagai pendingin pada proses permesinan untuk menjaga mutu produk. Macam-macam atau cara pemberian cutting fluid diantaranya dry, flood, MQL (Minimum Quantity Lubrication).

Sebagai teknologi yang relative baru, MQL menjanjikan keuntungan dari segi ekonomi sekaligus ramah lingkungan dengan meminimumkan penggunaan cutting fluid selama permesinan. Penggunaan MQL juga terbukti mampu menghasilkan permukaan yang lebih halus pada material yang berbeda yaitu AISI 4340 (Basuki, 2014), (Patole \& Kulkarni, 2018), AISI 304 (Zhang, Wen Liu, Zhang, \& Jiang, 2019) dan mild steel (Kedare, Borse, \& Shahane, 2014), TC4 (Li et al., 2019) dan lain-lain. Semua keunggulan MQL yang sudah disebutkan tetap berlaku walaupun diterapkan pada material yang berbeda.

Untuk mengurangi lebih lanjut penggunaan cutting fluid pada sistem MQL telah dibuat alat kendali berbasis Arduino oleh kolega kami pada kelompok riset (Dinata, 2019). Alat pengendali ini bekerja berdasarkan kendali suhu. Sebuah sensor dilekatkan pada sisi pahat dan mengirim sinyal ke pengendali. Jika suhu pahat telah mencapai 70 oC, kemudian cutting fluid disemprotkan oleh pompa melalui nozzle. Penyemprotan akan dihentikan otomatis jika suhu pahat sudah turun di bawah suhu 70 oC (Dinata, 2019).

\section{TUJUAN PENELITIAN}

Penelitian ini berupaya mengungkap efek pemberian cutting fluid dengan tambahan alat kendali temperatur yang telah dibuat terhadap sifat mampu mesin baja AISI 4340. Sifat mampu mesin yang menjadi fokus adalah kekasaran permukaan hasil pembubutan lurus. Jika dengan penambahan alat kendali pada sistem MQL ini terbukti mampu menaikkan mutu permukaan hasil pembubutan, maka akan didapat manfaat ganda yaitu pengurangan penggunaan cutting fluid dan perbaikan mutu benda kerja sekaligus.

\section{METODE PENELITIAN}

Metode yang digunakan yaitu dengan membandingkan pengaruh 3 (tiga) cara pemberian cutting fluid terhadap nilai kekasaran permukaan (Ra), yaitu flood, MQL manual, MQL otomasi. MQL manual pada peneltian ini maksudnya pemberian cutting fluid dengan sistem MQL namun mengalir terus menerus selama pembubutan berlangsung. Selain itu, ditambahkan variasi depth of cut dan komposisi campuran pendingin. Variasi depth of cut pada penelitian ini ada tiga, yaitu $1,6 \mathrm{~mm} ; 1,8 \mathrm{~mm}$; dan 2,0 mm. Komposisi campuran air dan dromus (bahan dasar cutting fluid) pada penelitian ini ada tiga, yaitu perbandingan $3: 7 ; 5: 5$; dan 7:3, dengan angka pertama merujuk terhadap volume air dan angka pembanding (kedua) merujuk terhadap volume minyak dromus.

Benda kerja baja AISI 4340 dengan panjang 100 $\mathrm{mm}$ dan diameter $35 \mathrm{~mm}$. Pahat tipe sisipan (insert) dari bahan karbida (carbide). Pembubutan lurus dilakukan pada mesin bubut konvensional. Kekasaran permukaan diukur dengan surface roughness tester yang mempunyai panjang langkah maksimum 12,5 $\mathrm{mm}$. Pengukuran kekasaran dilakukan pada sisi awal pembubutan, sisi tengah dan bagian akhir dari poros setelah dibubut dengan tiap bagian diulang pada empat kuadran berbeda kemudian dirata-rata. Tiap kombinasi parameter permesinan dilakukan pembubutan tiga kali demikian juga pengukurannya. Proses pengukuran dengan roughness tester ditunjukkan pada Gambar 1. Desain eksperimen mengikuti metode metode Taguchi orthogonal array L9 $\left(3^{3}\right)$. Jadi dengan sebanyak 27 kali eksperimen. Penggunaan metode Taguchi untuk optimasi parameter permesinan sudah banyak diterapkan oleh para peneliti sebelumnya, seperti Khanna (Khanna \& Davim, 2015), (Darsin \& Pasang, 2019). Bahkan Islam dan Parmanik melakukan perbandingan antara metode Taguchi terhadap desain eksperimen secara umum dan hasilnya membuktikan bahwa metode Taguchi mampu menghasilkan data yang akurat dengan jumlah eksperimen yang 
jauh lebih sedikit (Islam \& Pramanik, 2016). Sehingga diharapkan dapat menekan biaya dan resources seminimal mungkin (Fitri, 2009).

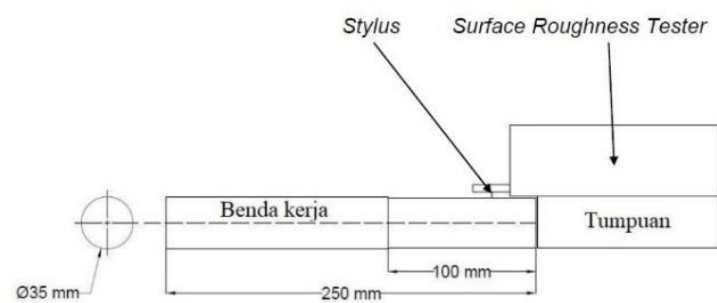

Gambar 1. Skema pengambilan data

\section{HASIL DAN PEMBAHASAN}

Data diambil pada permukaan menunjukkan perbandingan dengan pengaruh 3 (tiga) variabel penelitian terhadap nilai kekasaran permukaan $(\mathrm{Ra})$, dan dimasukkan ke dalam tabel acuan agar dapat dianalisa dapat dilihat pada Tabel 1.

Tabel 1. Rata-rata kekasaran permukaan

\begin{tabular}{|c|c|c|c|c|c|c|c|}
\hline \multirow[b]{2}{*}{ No } & \multicolumn{3}{|c|}{$\begin{array}{l}\text { Parameter } \\
\text { Kendali }\end{array}$} & \multicolumn{3}{|c|}{ Replikasi } & \multirow{2}{*}{$\begin{array}{c}\mathrm{Ra} \\
\text { rata-rata } \\
(\mu \mathrm{m})\end{array}$} \\
\hline & $\begin{array}{l}\text { Depth of } \\
\text { cut (mm) }\end{array}$ & $\begin{array}{c}\text { Komposisi } \\
\text { (Air: } \\
\text { Dromus) }\end{array}$ & Metode & 1 & 2 & 3 & \\
\hline 1 & 1.6 & $3: 7$ & $\begin{array}{c}\mathrm{MQL} \\
\text { Manual }\end{array}$ & 2.027 & 3.211 & 2.793 & 2.677 \\
\hline 2 & 1.6 & $5: 5$ & $\begin{array}{c}\text { MQL } \\
\text { Otomasi }\end{array}$ & 3,141 & 1.857 & 2.079 & 2.359 \\
\hline 3 & 1.6 & $7: 3$ & Flood & 2.038 & 2.628 & 2.792 & 2.486 \\
\hline 4 & 1.8 & $3: 7$ & $\begin{array}{l}\text { MQL } \\
\text { Otomasi }\end{array}$ & 1.923 & 1.938 & 1.962 & 1.943 \\
\hline 5 & 1.8 & $5: 5$ & Flood & 2.098 & 3.488 & 2.917 & 2,834 \\
\hline 6 & 1.8 & $7: 3$ & $\begin{array}{c}\text { MQL } \\
\text { Manual }\end{array}$ & 2.878 & 2.089 & 2.351 & 2,439 \\
\hline 7 & 2.0 & $3: 7$ & Flood & 2,782 & 2.030 & 2.111 & 2.308 \\
\hline 8 & 2.0 & $5: 5$ & $\begin{array}{c}\text { MQL } \\
\text { Manual }\end{array}$ & 2.757 & 2.197 & 2.575 & 2.510 \\
\hline 9 & 2.0 & $7: 3$ & $\begin{array}{c}\text { MQL } \\
\text { Otomasi }\end{array}$ & 2.030 & 2.376 & 1.416 & 1,941 \\
\hline
\end{tabular}

Tabel 1 percobaan di atas, bahwa percobaan no 9 menghasilkan nilai rata-rata kekasaran permukaan paling rendah dengan permukaan yang lebih halus dengan parameter kendali depth of cut 2,0 mm, komposisi air $7: 3$, dan metode MQL otomasi. Sedangkan pada percobaan no 5 menghasilkan nilai rata-rata kekasaran permukaan paling tinggi dengan permukaan yang kasar dengan parameter kendali depth of cut $1,8 \mathrm{~mm}$, komposisi air $5: 5$, dan metode flood. Foto kedua keadaan (terhalus dan terkasar) disajikan pada Gambar 2 dan Gambar 3. Tampak nyata perbedaan kekasaran di antara kedua hasil eksperimen tersebut. Hal ini juga mengindikasikan bahwa hasil pengujian dengan roughness tester bersesuaian dengan hasil pengamatan dengan metode fotografi. Sehingga analisis data pada Tabel 1 dapat dilanjutkan.

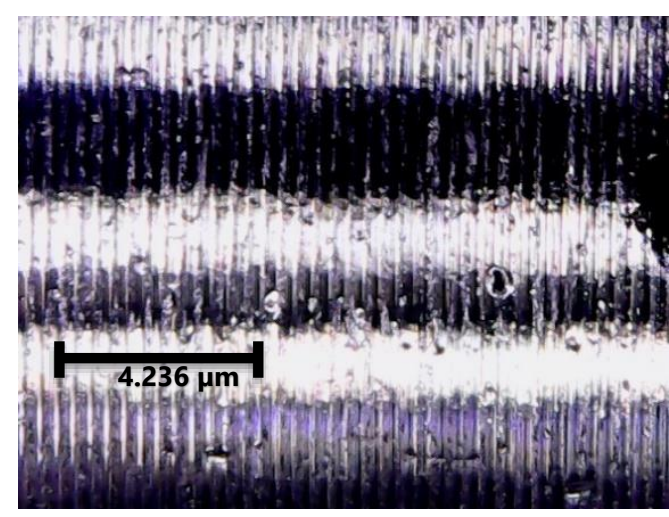

Gambar 2. Hasil percobaan no 9

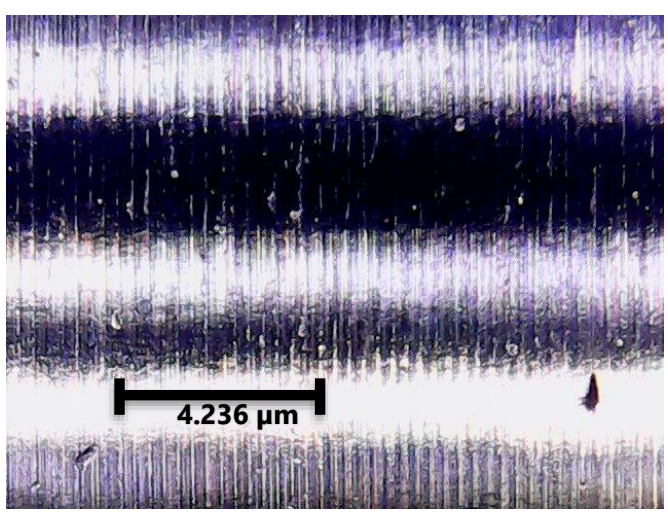

Gambar 3. Hasil percobaan no 5

\section{Hasil Optimasi}

Hasil perhitungan rata-rata pada masing masing dari faktor kendali dirangkum pada Tabel 2. Gambar 4 merupakan plot means dari setiap faktor.

Tabel 2. Rata-rata means setiap faktor kendali

\begin{tabular}{cccccc}
\hline \multirow{2}{*}{ SIMBOL } & FAKTOR & \multicolumn{3}{c}{ RATA-RATA } & \multirow{2}{*}{ SELISIH } \\
\cline { 3 - 5 } & KENDALI & LEVEL 1 & LEVEL 2 & LEVEL 3 & \\
\hline 1 & Depth of cut & 2,507 & 2,405 & $\mathbf{2 , 2 5 3}$ & $-0,255$ \\
2 & Komposisi & 2,309 & 2,568 & $\mathbf{2 , 2 8 9}$ & $-0,020$ \\
3 & Metode & 2,542 & $\mathbf{2 , 0 8 0}$ & 2,543 & $-0,462$ \\
& Rata-rata total & & \multicolumn{4}{c}{2,388} \\
\hline
\end{tabular}

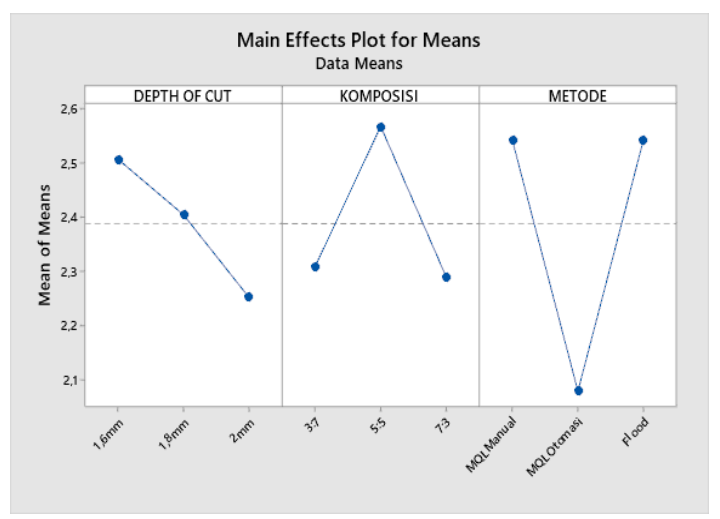

Gambar 4. Nilai plot rata-rata means 
Kombinasi level dari setiap faktor dapat dilihat pada Tabel 3.

Tabel 3. Kombnasi parameter respons optimum

\begin{tabular}{lll}
\hline Parameter & Level & Nilai \\
\hline Depth of cut & 3 & $2,0 \mathrm{~mm}$ \\
Komposisi & 3 & $7: 3$ \\
Metode & 2 & $\begin{array}{l}\text { MQL } \\
\text { Otomasi }\end{array}$ \\
\hline
\end{tabular}

Analisis variansi (ANOVA) adalah salah satu metode perhitungan statistik yang mampu mengungkap efek individual tiap faktor pada sebuah desain eksperiman terhadap variael yang diukur. Dalam hal ini, analisis variansi diterapkan untuk mengetahui pengaruh variable yang divariasi (depth of cut, komposisi cutting fluid dan metode pemberiannya) terhadap kekasaran permukaan. Hasilnya ditunjukkan pada Tabel 4 di bawah ini.

Tabel 4. Hasil analisis varian untuk means

\begin{tabular}{lllll}
\hline Sumber & DK & SS & MS & F $_{\text {hitung }}$ \\
\hline Depth of cut & 2 & 0,099 & 0,049 & 2,14 \\
Komposisi & 2 & 0,415 & 0,073 & 3,16 \\
Metode & 2 & 0,427 & 0,214 & 9,29 \\
Residual & 2 & 0,046 & 0,023 & \\
Total & 8 & & & \\
\hline
\end{tabular}

Persen kontribusi dari setiap faktor kendali digunakan untuk melihat seberapa pengaruh suatu parameter terhadap kekasaran permukaan disajikan pada Tabel 5 di bawah ini.

Tabel 5. Persen kontribusi tiap faktor kendali

\begin{tabular}{lll}
\hline Faktor & SS' $^{\prime}$ & P \\
\hline Depth of cut & 0,053 & $7,325 \%$ \\
Komposisi & 1,507 & $13,861 \%$ \\
Metode & 5,203 & $53,152 \%$ \\
Residual & & $25,662 \%$ \\
\hline Total & & $100 \%$ \\
\hline
\end{tabular}

Berdasarkan dari pengolahan data menggunakan metode Taguchi di atas maka dapat dibahas sebagai berikut:

Metode pemberian cutting fluid dengan MQL otomasi terbukti memberi pengaruh berarti terhadap permukaan hasil permesinan yakni mampu menghasilkan nilai kekasaran permukaan paling yang paling rendah dengan permukaan yang halus seperti ditunjukkan pada
Gambar 2. Pada penelitian ini, kontribusi metode pemberian cutting fluid berkontribusi paling besar $(53,152 \%)$ terhadap kehalusan permukaan (Tabel 5). Selanjutnya metode MQL otomasi mampu menghasilkan permukaan terhalus dibanding dua metode lainnya (Gambar 4). Dapat disimpulkan bahawa metode pemberian cutting fluid MQL otomasi dapat mendinginkan dan melumasi permukaan antar pahat dan benda kerja saat pemotongan terjadi. Akibatnya gesekan yang terjadi antara pahat dengan benda kerja berkurang. Sehingga laju kenaikan temperatur tetap rendah.

Faktor depth of cut merupakan faktor yang mempengaruhi hasil nilai kekasaran permukaan. Secara umum penggunaan depth of cut $2,0 \mathrm{~mm}$ menghasilkan nilai kekasaran permukaan yang lebih kasar dibandingan dengan depth of cut 1,6 $\mathrm{mm}$ dan $1,8 \mathrm{~mm}$. Akan tetapi dengan adanya penambahan cutting fluid permukaan yang lebih halus dapat diperoleh. Hal ini dikarenakan karena fungsi dari cutting fluid yang melumasi benda kerja sehingga gesekan antara benda kerja dengan pahat berkurang dan membuktikan bahwa penggunaan cutting fluid sangat membantu dalam mengurangi nilai kekasaran permukaan meskipun menggunakan depth of cut yang besar.

Selain depth of cut, komposisi juga merupakan faktor yang mempengaruhi nilai kekasaran permukaan. Komposisi yang optimal berdasarkan Gambar 2 yaitu $7: 3$ yang terdiri dari perbandingan $900 \mathrm{ml}$ air dan 400 cutting oil (dromus). Bahwa media pendingin air dengan campuran cutting oil mendapatkan harga ratarata kekasaran permukaan terendah. Hal ini disebabkan cutting fluid melumasi benda kerja secara sempurna. Pada penelitian ini penggunaan campuran perbandingan $900 \mathrm{ml}$ air dan 400 cutting oil mengakibatkan gesekan antara pahat dan benda kerja dapat dikurangi dan tatal yang dihasilkan tidak menempel pada benda kerja sehingga menghasilkan nilai kekasaran permukaan yang rendah. Campuran yang lebih kaya air menghasilkan cutting fluid yang lebih encer sehingga lebih mudah disemprotkan oleh pompa melalui nozzle. Akibatknya, pelumasan dan pendinginan lebih efektif karenanya cutting fluid melumasi benda kerja dan pahat secara merata dan tepat sasaran. 


\section{SIMPULAN}

Penggunaan metode pemberian cutting fluid menggunakan MQL dengan penambahan sistem kendali (otomasi) terbukti paling efektif untuk menghasilkan kekasaran permukaan pembubutan paling rendah. Selanjutnya, kombinasi parameter permesinan yang menghasilkan kekasaran permukaan paling minimum sampai dengan 1,941 $\mu \mathrm{m}$ diperoleh jika permesinan dengan MQL dengan sistem kendali, depth of cut 2,0 mm, dan komposisi air terhadap minyak pada cutting fluid 7:3.

\section{DAFTAR PUSTAKA}

Ali, S.M., Dhar, N.R., Dey, S. K. (2011). Effect of Minimum Quantity Lubrication (Mql) on Cutting Performance in Turning Medium Carbon Steel By Uncoated Carbide Insert At Different Speed-Feed Combinations. Advances in Production Engineering and Management, 6(3), 185-196. Retrieved from http://maja.unimb.si/files/apem/APEM6-3_185-196.pdf

Basuki, B. (2014). Pengaruh Metode Minimum Lubrication Keausan Pahat dan Kekasaran Permukaan Benda Kerja AISI 4340. Teknologi, 7(2), 112-117.

Darsin, M., \& Pasang, T. (2019). Drillability of Titanium Alloy 6246 from Surface Quality Perspective. Material Science Research India, 16(1), 76-85. https://doi.org/10.13005/msri/160111

Dinata, G. G. S. (2019). Perancangan sistem kendali pemberian fluida permesianan berbasis MQL pada mesin bubut dan analisis performanya. Universitas Jember.

Fitria, N. (2009). Analisis Metode Desain Eksperimen Taguchi dalam Optimasi Karakteristik Mutu. Universitas Islam Negeri Maulana Malik Ibrahim Malang.

Islam, M. N., \& Pramanik, A. (2016). Comparison of Design of Experiments via Traditional and Taguchi Method. Journal of Advanced Manufacturing Systems, 15(3), 151-160.

https://doi.org/10.1142/S021968671650 0116
Jiang, Z., Zhou, F., Zhang, H., Wang, Y., \& Sutherland, J. W. (2015). Optimization of machining parameters considering minimum cutting fluid consumption. Journal of Cleaner Production, 108, 183191.

https://doi.org/10.1016/j.jclepro.2015.0 6.007

Kedare, S. B., Borse, D. R., \& Shahane, P. T. (2014). Effect of Minimum Quantity Lubrication (MQL) on Surface Roughness of Mild Steel of 15HRC on Universal Milling Machine. Procedia Materials Science, 6(Icmpc), 150-153. https://doi.org/10.1016/j.mspro.2014.07 .018

Khanna, N., \& Davim, J. P. (2015). Design-ofexperiments application in machining titanium alloys for aerospace structural components. 61, 280-290.

Li, M., Yu, T., Yang, L., Li, H., Zhang, R., \& Wang, W. (2019). Parameter optimization during minimum quantity lubrication milling of TC4 alloy with graphenedispersed vegetable-oil-based cutting fluid. Journal of Cleaner Production, 209, 1508-1522.

https://doi.org/10.1016/j.jclepro.2018.1 1.147

Patole, P. B., \& Kulkarni, V. V. (2018). Optimization of Process Parameters based on Surface Roughness and Cutting Force in MQL Turning of AISI 4340 using Nano Fluid. Materials Today: Proceedings, 5(1), 104-112. https://doi.org/10.1016/j.matpr.2017.11. 060

Upadhyay, V., Jain, P. K., \& Mehta, N. K. (2012). Minimum Quantity Lubrication Assisted Turning- An Overview Machining with minimum quantity lubrication: a step towards green manufacturing Vikas Upadhyay *, P. K. Jain and N. K. Mehta. (January). https://doi.org/10.2507/daaam.scibook. 2012.39

Zhang, Z., Wen, C., Liu, Y., Zhang, D., \& Jiang, Z. (2019). End Milling of AISI 304 steel using Minimum Quantity Lubrication. (May). 